\title{
Follow-Up Survey on Functionality of Nutrition Documentation and Ordering Nutrition Therapy in Currently Available Electronic Health Record Systems
}

\author{
Vincent W. Vanek, MD, FACS, FASPEN ${ }^{1}$; Phil Ayers, PharmD, BCNSP, FASHP² \\ Pamela Charney, PhD, RD, CHTS-CP ${ }^{3}$; Michael Kraft, PharmD, BCNSP ${ }^{4}$; \\ Ronelle Mitchell, MA, RD, CNSC ${ }^{5}$; Steven Plogsted, PharmD, BCNSP, CNSC $^{6}$; \\ Jason Soden, MD ${ }^{7}$; Charles W. Van Way III, MD, FACS, FASPEN ${ }^{8}$; \\ Jacqueline Wessel, MEd, RDN, CNSC, CSP, CLE ${ }^{9}$; John Winter, PharmD ${ }^{10}$; \\ Sue Kent, MS, RDN, LD ${ }^{11}$; Peggy Turner, MS, RD, LD, FAND ${ }^{12}$; \\ Jean Bouche, RD $^{13}$; Donna Quirk, RD $^{14}$; and Douglas L. Seidner, MD, AGAF, FACG, CNSC $^{15}$
}

Nutrition in Clinical Practice

Volume 31 Number 3

June 2016 401-415

(C) 2016 American Society

for Parenteral and Enteral Nutrition DOI: $10.1177 / 0884533616629619$ ncp.sagepub.com

hosted at

online.sagepub.com

(S)SAGE

\begin{abstract}
Background: This is a follow-up survey to reassess the safety and efficacy of nutrition content in the available electronic health record (EHR) systems. Materials and Methods: Members of the American Society for Parenteral and Enteral Nutrition (A.S.P.E.N.), American Society for Nutrition, and the Academy for Nutrition and Dietetics were asked to participate in an online survey. The survey included questions from a 2012 EHR survey on the safety and efficacy in 5 nutrition content areas as well as questions from previous 2003 and 2011 A.S.P.E.N. parenteral nutrition (PN) surveys. Results: Percent of respondents using an EHR and using the EHR for less than 1 year increased between 2012 and $2014(86 \%-94 \%, P<.05 ; 11 \%-16 \%, P<.05$, respectively). However, there was no improvement in the safety and efficacy of the 5 nutrition content areas, with a significant decrease in 2 of these areas, ordering oral nutrition supplements and ordering PN. The top-rated EHR vendors had a higher average favorable response rate in regards to safety and efficacy in the nutrition content areas but even the top-rated EHR vendor had only a $60 \%$ average in favorable responses. Reported use of electronic PN ordering and a direct interface between the EHR and the automated compounding device (ACD) significantly increased from 2003 to 2011 to 2014 (29\% to $33 \%$ to $63 \%$ and $16 \%$ to $19 \%$ to $28 \%$, respectively, $P<.05)$. Conclusions: This is a call to action to nutrition support clinicians, societies, and organizations to proactively be involved in initiatives to educate clinicians and collaborate with EHR vendors to enhance the EHR systems to improve the safety and efficacy of providing nutrition therapy in hospitalized patients. (Nutr Clin Pract. 2016;31:401-415)
\end{abstract}

\section{Keywords}

electronic health records; electronic medical record; safety; efficacy; nutrition therapy; nutrition documentation; nutritional support; medical order entry systems; health information management

In 2012, a survey of the members of the American Society for Parenteral and Enteral Nutrition (A.S.P.E.N.) was conducted regarding the content and functionality of commercially available electronic health record (EHR) systems for documenting and ordering nutrition therapy. ${ }^{1}$ The article concluded that the clinical nutrition content and functionality in these EHRs needed enhancement and that nutrition support clinicians needed to be actively involved in this optimization process. In July 2014, the A.S.P.E.N. Clinical Nutrition Informatics Committee (CNIC) was formed and was tasked with the following:

1. Evaluate the clinical nutrition content and functionality in the major commercially available EHRs
2. Identify health information technology (HIT) and EHR issues that affect patient safety and system effectiveness in nutrition support management

3. Collaborate with other healthcare organizations and major EHR vendors to address identified HIT/EHR issues

4. Provide education and support for A.S.P.E.N. members and other nutrition and nutrition support clinician in using EHRs

The A.S.P.E.N. CNIC decided to repeat the 2012 EHR survey of the content and functionality of commercially available EHRs for documenting and ordering nutrition therapy but wanted to expand the scope to include other nutrition clinicians outside of A.S.P.E.N. This article presents the results of 
this follow-up survey. This document has been approved by the A.S.P.E.N. Board of Directors.

\section{Methods}

The A.S.P.E.N. CNIC reviewed the tool used in the first survey. Several questions regarding dietitians and pharmacists ordering nutrition therapy and hospital policies and procedures regarding these activities (questions 7-13 in the 2012 survey) were removed. ${ }^{1}$ Several informatics-specific questions from a previous A.S.P.E.N. survey ${ }^{2}$ on ordering, compounding, and administering parenteral nutrition (PN) were added (questions 7-12), and a question comparing the time to complete daily work before and after the EHR implementation (question 18) was added (Table 1). SurveyMonkey was used to administer the survey. An email with a link to the survey was sent to the groups surveyed. In the 2012 survey, the survey was left open for 3 weeks with a reminder email half way through the 3 weeks. For the 2014 survey, the survey was left open for approximately 2 weeks for each group surveyed without a reminder. Four different groups of nutrition clinicians were surveyed over sequential time periods: (1) A.S.P.E.N. members (September 25, 2014, to October 10, 2014), (2) non-A.S.P.E.N. members in the A.S.P.E.N. database (October 13, 2014, to October 27, 2014), (3) Medical Nutrition Council members of the American Society for Nutrition (ASN) (October 27, 2014, to November 12, 2014), and (4) specific Dietetic Practice Groups of the Academy of Nutrition and Dietetics (the Academy), including the Clinical Nutrition Managers, Dietitians in Nutrition Support, Pediatric Nutrition, and Medical Nutrition groups (December 8, 2015, to January 5, 2015, extended longer than other groups due to inclusion of the holiday period).

Overall EHR performance data were obtained on the most commonly used EHR products by acute care hospitals from an independent, consumer advocacy company named KLAS (Orem, UT). ${ }^{1,3}$ This company collects survey data from healthcare system leaders using different EHR products from across the United States and annually publishes a ranking of the EHRs based on performance scores from the survey data. Further description of the company and its method can be found in the 2012 A.S.P.E.N. survey article. ${ }^{1}$ The December 2011 KLAS report ranking was used in the 2012 survey analysis, and this was compared with the December 2012, December 2013, and December 2014 rankings in the analysis of the follow-up survey data. For reporting purposes, each of the 8 EHR companies named in the 2012 survey was de-identified by assigning each a letter of the alphabet. The 2014 survey included 13 EHR vendor products by name in the survey and for reporting purposes used the same letter designations as in the 2012 survey report and added additional letters for those EHR vendor products not named specifically in the 2012 survey.

The 2012 A.S.P.E.N. membership EHR survey responses were compared with the 2014 A.S.P.E.N. membership survey responses and the 2014 non-A.S.P.E.N. membership survey responses. Responses from all 3 EHR survey groups were combined for subgroup analysis to increase statistical power. The data from the A.S.P.E.N. survey were analyzed using the reporting tools within SurveyMonkey. Statistical analysis was performed on the A.S.P.E.N. survey responses using available $\chi^{2}$ calculators to analyze differences in survey responses between groups. Test statistics were considered significant if the probability of a chance finding was $<5 \%(P<.05)$. The responses to the 5 questions regarding the safety and effectiveness of the different nutrition components in the EHR, questions 13-17 (Table 1), were converted to dichotomous results by considering responses of "highly safe and effective" and "moderately safe and effective" as "favorable" responses and the other 3 responses as "unfavorable" responses.

\section{Results}

The overall survey response rate for the 2012 EHR survey was significantly higher than the response rates for the 2014 survey

From ${ }^{1}$ American Society for Parenteral and Enteral Nutrition (A.S.P.E.N.) Clinical Nutrition Informatics Committee (CNIS), St Elizabeth Youngstown Hospital, Youngstown, Ohio, USA; ${ }^{2}$ A.S.P.E.N. CNIS, Mississippi Baptist Medical Center, Jackson, Mississippi; ${ }^{3}$ A.S.P.E.N. CNIS, Bellevue College, Bellevue, Washington; ${ }^{4}$ A.S.P.E.N. CNIS, University of Michigan, Ann Arbor, Michigan, USA; ${ }^{5}$ A.S.P.E.N. CNIS, Cleveland Clinic, Cleveland, Ohio, USA; ${ }^{6}$ A.S.P.E.N. CNIS, Nationwide Children's Hospital, Columbus, Ohio, USA; ${ }^{7}$ A.S.P.E.N. CNIS, University of Colorado School of Medicine, Aurora, Colorado, USA; ${ }^{8}$ A.S.P.E.N. CNIS, University of Missouri, Kansas City, Missouri, USA; ${ }^{9}$ A.S.P.E.N. CNIS, Cincinnati Children's Hospital Medical Center, Cincinnati, Ohio, USA; ${ }^{10}$ A.S.P.E.N. CNIS, Director of Informatics, Central Admixture Pharmacy Services, Puyallup, Washington, USA; ${ }^{11}$ Academy of Nutrition and Dietetics (Academy) Nutrition Informatics Committee (NIC), Clinical Systems Analyst, Center for Human Nutrition, Cleveland Clinic, Cleveland, Ohio, USA; ${ }^{12}$ Academy NIC, University of Oklahoma Health Sciences Center, Oklahoma City, Oklahoma, USA; ${ }^{13}$ Academy NIC, Hospital Sisters Health System Eastern Wisconsin Division, Green Bay, WI, USA; ${ }^{14}$ Chair, Academy NIC Interoperability Standards Committee, Lexington Medical Center, West Columbia, South Carolina, USA; and ${ }^{15}$ American Society for Nutrition, Nutrition Education Committee, Vanderbilt University Medical Center, Nashville, Tennessee, USA.

This article reports an update from a 2012 survey reported on by Vanek and colleagues. Some material may be similar to or the same as that published in 2012 and is used with permission from A.S.P.E.N. See reference 1 for full background information.

Financial disclosure: None declared.

This article originally appeared online on February 26, 2016.

Corresponding Author:

Vincent W. Vanek, MD, FACS, FASPEN, Department of Surgical Education, St Elizabeth Youngstown Hospital, 1044 Belmont Ave, PO Box 1790, Youngstown, OH 44501-1790, USA.

Email: vince_vanek@mercy.com 
Table 1. 2014 EHR Survey Questions With Responses in Parentheses or Bullets Below the Question.

1. What is your discipline? (dietitian, physician, nurse, pharmacist, other)

2. Where do you work? (United States or outside of the United States)

3. What setting do you mainly work in? (hospital only, outpatient [clinic/office] only, hospital and outpatient, home care)

4. How long have you been working in nutrition support? (1-2 years, 3-5 years, 5-10 years, over 10 years)

5. What electronic health record (EHR) vendor do you use for nutrition support? (choices were 1 of 12 vendors, "other" vendor [vendor specified in free text field], or "none" [respondents not using EHR were directed to not answer subsequent survey questions]; respondent could choose more than 1 vendor)

6. How long has your hospital been using an EHR? (less than 1 year, 1-3 years, 3-5 years, 5-10 years, over 10 years)

7. Which of the following BEST describes the PN ordering method at your organization? (handwritten standard order form, electronic standard order entry form, handwritten orders [not standardized], electronic order entry form [not standardized])

8. If an electronic order entry process is used, which of the following is applied to limit order entry errors (check all that apply)? (limit space in free text fields, use check boxes instead of free text, auto-populate as many fields as possible, maintain entire order on a single screen, dosing guidelines and decision support tools are built into the system, order cannot be submitted until all required fields are complete, other [please specify])

9. Does your organization's pharmacy have a computer software system (i.e., NOT the PN compounder system) separate from the organization's electronic medical record (EMR; used for order entry, test results, consults, etc.)? (yes or no)

10. How is PN order data entered into the pharmacy system? (automatic electronic interface with organization's order entry system, barcode entry from a printed label/requisition, manual entry from a printed label/requisition [technician], manual entry from a printed label/requisition [pharmacist], manual entry from a written order form [technician], manual entry from a written order form [pharmacist], other [please specify])

11. Does your organization (or outsourced vendor) use an automated compounding device (ACD) to prepare PN? (yes, no, or don't know)

12. How are the data entered into the ACD? (manual entry [technician], manual entry [pharmacist], automatic electronic interface with organization's order entry system)

13. How would you rate the safety and effectiveness of nutrition documentation in your EHR?

- Highly safe and effective

- Moderately safe and effective

- Usually safe and effective, but opportunities for improvement

- Needs improvements before I would consider it completely safe and effective

- Serious safety and effectiveness concerns and needs urgent changes

14. How would you rate the safety and effectiveness of ordering of oral diets in your EHR? (responses same as question 13)

15. How would you rate the safety and effectiveness of ordering oral supplements in your EHR? (responses same as question 13)

16. How would you rate the safety and effectiveness of ordering tube feedings in your EHR? (responses same as question 13)

17. How would you rate the safety and effectiveness of ordering parenteral nutrition in your EHR? (responses same as question 13)

18. Comparing prior to EHR implementation, how long does it take you to complete your work? (longer amount time, about the same amount time, lesser amount time)

19. What do you most like about the nutrition content of your EHR? (free text field)

20. What do you least like about the nutrition content of your EHR? (free text field)

$\mathrm{PN}$, parenteral nutrition.

( $14.9 \%$ vs $0.7 \%-6.4 \%, P<.05)$ even when comparing response rates from only the A.S.P.E.N. members $(14.9 \%$ vs $6.4 \%, P<$ .05 ) (Table 2). Most respondents in both the 2012 and 2014 surveys were dietitians ( $78 \%$ vs $80 \%-90 \%)$. The distribution of disciplines among the respondents for the 2 A.S.P.E.N. member surveys was representative of the distribution within the A.S.P.E.N. membership except that the percentage of dietitians was slightly higher and physicians slightly lower in the respondents compared with the distribution within the membership. Most respondents practiced within the United States and practiced in the hospital setting, either alone or in combination with the outpatient setting. Over half of the respondents reported working in nutrition support for over 10 years (Table 3 ).

A significantly higher proportion of the A.S.P.E.N. membership respondents were using an EHR in the 2014 A.S.P.E.N. membership survey compared with the 2012 A.S.P.E.N. membership survey $(94 \%$ vs $86 \%, P<.05)$. (Table 3 ) Also, in those respondents using an EHR, there was a significantly higher percentage of respondents that were using their EHR for $<1$ year in the 2014 A.S.P.E.N. membership survey compared with the 2012 A.S.P.E.N. membership survey $(16 \%$ vs $11 \%, P<$ .05) (Table 4).

Comparing the 2014 KLAS-ranked EHR vendors with the EHR vendors used by the 2014 A.S.P.E.N. and non-A.S.P.E.N. member respondents, there was a significant correlation between the KLAS ranking and the frequency of vendor use (first ranked, 36.5\%; second ranked, 22.5\%; third ranked, $7.6 \%$; fourth ranked, $15.9 \%$; fifth ranked, $5.1 \%$; and sixth ranked, $5.3 \% ; P<.001)$. There was a significant increase in the use of one of the top 2 rated EHR vendors from the 2012 
Table 2. Survey Response Rates.

\begin{tabular}{lccc}
\hline Characteristic & No. Sent Survey & No. of Respondents & Response Rate, \% \\
\hline 2012 EHR survey & & & \\
A.S.P.E.N. members & 5810 & 864 & $14.9^{\mathrm{a}}$ \\
2014 EHR survey & & 393 & $6.4^{\mathrm{a}, \mathrm{b}}$ \\
A.S.P.E.N. members & 6179 & 732 & $1.7^{\mathrm{a}}$ \\
Non-A.S.P.E.N. members & 43,913 & 236 & 0.7 \\
A.S.P.E.N. database & 33,165 & 28 & 1.3 \\
American Society for Nutrition $^{\mathrm{d}}$ & 2189 & 468 & 5.5 \\
Academy of Nutrition and Dietetics $^{\mathrm{e}}$ & 8559 & & \\
\hline
\end{tabular}

A.S.P.E.N., American Society for Parenteral and Enteral Nutrition; EHR, electronic health record.

${ }^{a} P<.05$ when compared with 2012 A.S.P.E.N. member survey to 2014 A.S.P.E.N. member survey to 2014 non-A.S.P.E.N. member survey.

${ }^{\mathrm{b}} P<.05$ when compared with 2012 A.S.P.E.N. member survey to 2014 A.S.P.E.N. member survey.

'Non-A.S.P.E.N. members in A.S.P.E.N.'s database.

${ }^{\mathrm{d}}$ Not entire membership but just their Medical Nutrition Council, which are mostly members who practice clinically.

${ }^{\mathrm{e}}$ Formerly the American Dietetic Association - not entire membership but to the Clinical Nutrition Managers, Dietitians in Nutritional Support, Medical Nutrition Practice Group, and Pediatric Nutrition Dietetic Practice Group.

Table 3. Demographics of EHR Survey Responders. ${ }^{\text {a }}$

\begin{tabular}{|c|c|c|c|}
\hline \multirow[b]{2}{*}{ Characteristic } & \multirow{2}{*}{$\begin{array}{c}2012 \text { Survey, } \\
\text { No. }(\%)\end{array}$} & \multicolumn{2}{|c|}{2014 Survey, No. (\%) } \\
\hline & & A.S.P.E.N. Members & Non-A.S.P.E.N. Members \\
\hline \multicolumn{4}{|l|}{ Discipline } \\
\hline Dietitians & $676(78)$ & $315(80)$ & $660(90)$ \\
\hline Physicians & $51(6)$ & $11(3)$ & $30(4)$ \\
\hline Pharmacists & $98(11.5)$ & $51(13)$ & $28(4)$ \\
\hline Nurses/NPs & $35(4)$ & $14(3.5)$ & $9(1)$ \\
\hline Other & $4(0.5)$ & $2(0.5)$ & $5(1)$ \\
\hline \multicolumn{4}{|l|}{ Location } \\
\hline United States & $790(91)$ & $371(94)$ & $671(92)$ \\
\hline Outside United States & $74(9)$ & $22(6)$ & $61(8)$ \\
\hline \multicolumn{4}{|l|}{ Practice setting } \\
\hline Hospital only & $605(70)$ & $291(74)$ & $411(56)$ \\
\hline Outpatient only & $19(2)$ & $8(2)$ & $92(13)$ \\
\hline Hospital and outpatient & $189(22)$ & $87(22)$ & $212(29)$ \\
\hline Home care & $51(6)$ & $7(2)$ & $17(2)$ \\
\hline \multicolumn{4}{|c|}{ Length of time working in nutrition support } \\
\hline $1-2$ years & $82(9)$ & $43(11)$ & $86(12)$ \\
\hline $3-5$ years & $118(14)$ & $44(11)$ & $77(11)$ \\
\hline $5-10$ years & $183(21)$ & $67(17)$ & $137(18)$ \\
\hline$>10$ years & $481(56)$ & $239(61)$ & $432(59)$ \\
\hline \multicolumn{4}{|l|}{ Using an EHR? } \\
\hline Yes & $742(86)$ & $347(94)^{b}$ & $577(90)$ \\
\hline No & $122(14)$ & $17(5)$ & $64(10)$ \\
\hline
\end{tabular}

A.S.P.E.N., American Society for Parenteral and Enteral Nutrition; EHR, electronic health record; NP, nurse practitioner.

${ }^{a}$ Not all respondents answered all survey questions.

${ }^{\mathrm{b}} P<.01$ using $\chi^{2}$ analysis comparing the 2014 A.S.P.E.N. member survey with the 2012 A.S.P.E.N. member survey.

A.S.P.E.N. membership survey to the 2014 A.S.P.E.N. membership survey (43\% [316/742] vs 66\% [226/342], $P<.05)$. Comparing the A.S.P.E.N. membership surveys from $2012-$ 2014, several EHR vendors had a significant increase in the percentage of respondents using their product. Vendor F's product rank tied for sixth in the 2011 KLAS ranking, but the vendor retired this product and came out with a new product, listed as vendor L in the 2014 survey. The newer product 
Table 4. Length of Time EHR Used. ${ }^{\text {a }}$

\begin{tabular}{|c|c|c|c|}
\hline \multirow[b]{2}{*}{ Characteristic } & \multirow{2}{*}{$\frac{2012 \text { Survey, No. }(\%)}{\text { A.S.P.E.N. Members }}$} & \multicolumn{2}{|c|}{2014 Survey, No. (\%) } \\
\hline & & A.S.P.E.N. Members & Non-A.S.P.E.N. Members \\
\hline \multicolumn{4}{|c|}{ Length of time EHR in use } \\
\hline$<1$ year & $69(11)$ & $47(16)^{b}$ & $50(12)$ \\
\hline $1-3$ years & $131(22)$ & $76(26)$ & $120(29)$ \\
\hline $3-5$ years & $134(22)$ & $64(22)$ & $104(25)$ \\
\hline $5-10$ years & $170(28)$ & $67(23)$ & $82(20)$ \\
\hline$>10$ years & $104(17)$ & $37(13)$ & $55(14)$ \\
\hline
\end{tabular}

A.S.P.E.N., American Society for Parenteral and Enteral Nutrition; EHR, electronic health record.

${ }^{\mathrm{a}}$ Not all respondents answered all survey questions.

${ }^{\mathrm{b}} P<.05$ comparing percentage of respondents using EHR $<1$ year compared with 2012 survey but no significant difference in any of the other time frames.

Table 5. EHR Vendors Used by Respondents and Comparison of the 2011-2014 KLAS EHR Rankings.

\begin{tabular}{|c|c|c|c|c|c|c|c|}
\hline \multirow[b]{2}{*}{ EHR Vendor } & \multirow{2}{*}{$\frac{2012 \text { Survey }}{\begin{array}{c}\text { A.S.P.E.N. } \\
\text { Members }\end{array}}$} & \multicolumn{2}{|c|}{2014 Survey } & \multicolumn{4}{|c|}{ KLAS Ranking (Overall Score $0 \%-100 \%)^{\mathrm{b}}$} \\
\hline & & $\begin{array}{l}\text { A.S.P.E.N. } \\
\text { Members }\end{array}$ & $\begin{array}{c}\text { Non-A.S.P.E.N. } \\
\text { Members }\end{array}$ & 2014 & 2013 & 2012 & 2011 \\
\hline $\mathrm{A}$ & $170(23)$ & $139(41)^{c}$ & $223(35)$ & $1(89.3)$ & $1(88.5)$ & $1(90.5)$ & $1(90.3)$ \\
\hline B & 146 (19) & $87(25)^{c}$ & $136(21)$ & $2(79.1)$ & $2(78.6)$ & $2(78.3)$ & $2(78.5)$ \\
\hline $\mathrm{C}$ & $26(4)$ & $22(6)^{c}$ & $29(5)$ & $5(64.9)$ & $6(70.0)$ & $4(73.0)$ & $3(77.2)$ \\
\hline $\mathrm{D}$ & $51(7)$ & $27(8)$ & $48(7)$ & $3(75.4)$ & $3(71.5)$ & $5(68.6)$ & $4(73.0)$ \\
\hline $\mathrm{E}$ & $114(15)$ & $48(14)$ & $110(17)$ & $4(67.2)$ & $5(70.5)$ & $6(65.5)$ & $5(71.6)$ \\
\hline$F^{d}$ & $66(9)$ & - & - & - & - & - & T6 (67.7) \\
\hline $\mathrm{G}$ & $0(0)$ & $4(1)$ & $3(0.5)$ & NR & NR & NR & T6 (67.7) \\
\hline $\mathrm{H}$ & $6(1)$ & $11(3)^{c}$ & $24(4)$ & NR & NR & NR & $8(57.8)$ \\
\hline I & - & $1(0.3)$ & $4(1)$ & NR & NR & NR & NR \\
\hline $\mathrm{J}$ & - & $1(0.3)$ & $6(1)$ & NR & NR & NR & NR \\
\hline $\mathrm{K}$ & - & $3(0.9)$ & $7(1)$ & NR & NR & NR & NR \\
\hline$L^{d}$ & - & $21(6)$ & $32(5)$ & $6(59.2)$ & $4(70.7)$ & $3(76.8)$ & - \\
\hline M & - & $12(4)$ & $20(3)$ & NR & NR & NR & NR \\
\hline X (other/unknown) & $163(22)$ & $37(11)$ & $125(20)$ & NR & NR & NR & NR \\
\hline No. of respondents & $742^{\mathrm{e}}$ & $342^{\mathrm{e}}$ & $641^{\mathrm{e}}$ & NR & NR & NR & NR \\
\hline
\end{tabular}

2011, 2012, 2013, 2014 "Best in KLAS Awards: Software and Services," Accessed September 2015. C 2016 KLAS Enterprises, LLC. All rights reserved. www.KLASresearch.com. A.S.P.E.N., American Society for Parenteral and Enteral Nutrition; EHR, electronic health record; NR, not ranked. ${ }^{a}$ Not all respondents answered all survey questions. Values are presented as number (\%) unless otherwise indicated.

${ }^{b}$ Description of KLAS and its scoring system found in the 2012 survey paper (Vanek VW. Providing nutrition support in the electronic health record era: the good, the bad, and the ugly. Nutr Clin Pract. 2012;27(6):718-737).

${ }^{\mathrm{c}} P<.05$ comparing 2012 and 2014 A.S.P.E.N. member surveys.

${ }^{\mathrm{d}}$ Same vendor but had a different EHR application in the 2012 survey (F) than in the 2014 survey (L).

${ }^{\text {e}}$ The 2012 survey respondents could choose only 1 vendor, but in the 2014 survey, respondents could pick more than 1 vendor if using multiple vendors, so total number of vendors is greater than the number of respondents.

ranked fourth in 2014. There were a significant percentage of respondents in both surveys $(22 \%$ in 2012 and $11 \%-20 \%$ in 2014) that chose "Other" and entered a free text comment (Table 5). Reviewing these comments under "Other," some respondents did not know the name of their EHR, knew it by a different name than the name of the EHR vendor listed in the responses, or had a different EHR other than what was listed in the response to this question. Unfortunately, the respondents who were using an EHR vendor that was named in the responses could not be reassigned to that EHR vendor group.
The percentage of favorable responses was not significantly different between the 2012 and 2014 A.S.P.E.N. membership surveys for nutrition documentation, ordering oral diets, and ordering tube feedings (Table 6). However, it significantly decreased for ordering oral nutrition supplements (ONS) and ordering PN. The percentage of favorable responses for all 5 nutrition content areas was higher for the 2014 non-A.S.P.E.N. members compared with the 2014 A.S.P.E.N. members, but these differences were not statistically significant, except for ordering PN. Combining the responses from all 3 surveys, 
Table 6. Favorable Responses to Nutrition Documentation Functionality by Length of Time EHR Used and by Vendor. ${ }^{\text {a }}$

\begin{tabular}{|c|c|c|c|c|}
\hline \multirow[b]{3}{*}{ Characteristic } & \multicolumn{4}{|c|}{ No. (\%) of Favorable Responses } \\
\hline & \multirow{2}{*}{$\begin{array}{c}2012 \text { Survey } \\
\begin{array}{c}\text { A.S.P.E.N. } \\
\text { Members }(n=608)\end{array}\end{array}$} & \multicolumn{2}{|c|}{2014 Survey } & \multirow[b]{2}{*}{ Total $(\mathrm{N}=1310)$} \\
\hline & & $\begin{array}{c}\text { A.S.P.E.N. } \\
\text { Members }(n=291)\end{array}$ & $\begin{array}{l}\text { Non-A.S.P.E.N. } \\
\text { Members }(n=411)\end{array}$ & \\
\hline Nutrition documentation & $306(50)$ & $137(47)$ & $222(54)$ & $665(51)$ \\
\hline Ordering oral diets & $345(57)$ & $146(50)$ & $232(56)$ & $723(55)^{\mathrm{b}}$ \\
\hline Ordering oral nutrition supplements & $379(62)$ & $158(54)^{\mathrm{c}}$ & $240(58)$ & $777(59)^{\mathrm{d}}$ \\
\hline Ordering tube feedings & $339(56)$ & $143(49)$ & $225(55)$ & $707(54)$ \\
\hline Ordering parenteral nutrition & $335(55)$ & $128(44)^{\mathrm{c}}$ & $220(54)^{\mathrm{e}}$ & $683(52)$ \\
\hline
\end{tabular}

A.S.P.E.N., American Society for Parenteral and Enteral Nutrition; EHR, electronic health record.

"Not all respondents answered all survey questions. "Favorable Responses" is a combination of the "Highly" and "Moderately" responses, and

"Unfavorable Responses" is a combination of "Usually," "Needs improvements," and "Serious concerns" responses.

${ }^{\mathrm{b}} P<.05$ - ordering oral diets responses significantly better compared with nutrition documentation but not significantly different from any other nutrition content areas.

${ }^{\mathrm{c}} P<.05$ comparing 2014 A.S.P.E.N. member survey vs 2012 A.S.P.E.N. member survey.

${ }^{\mathrm{d}} P<.05$ - ordering oral nutrition supplements responses significantly better compared with each of the other 4 nutrition content areas.

${ }^{\mathrm{e}} P<.05$ comparing 2014 A.S.P.E.N. member survey vs 2014 non-A.S.P.E.N. member survey.

2012 A.S.P.E.N. members, 2014 A.S.P.E.N. members, and 2014 non-A.S.P.E.N. members, ordering ONS had a significantly higher percentage of favorable responses compared with each of the other 4 nutrition content areas. Ordering oral diets had a significantly higher percentage of favorable responses compared with nutrition documentation but was not significantly different compared with ordering tube feedings or ordering PN. However, there were no significant differences in comparison of the percentage of favorable responses between any of the other nutrition content areas.

The favorable responses for each of the 5 nutrition content areas combining all 3 surveys were compared based on discipline, length of time EHR was in use, and EHR vendor (Table 7). The percentage of favorable responses for nutrition documentation was significantly higher for dietitians and significantly lower for pharmacists compared with the other disciplines combined. However, there were no other differences in responses by discipline for the other 4 nutrition content areas. For all 5 nutrition content areas, the respondents using their EHR for 1-3 years and respondents using their EHR for $>10$ years had a significantly higher percentage of favorable responses compared with the respondents using their EHR $<1$ year. While there was a trend toward an increasing percentage of favorable responses with increased lengths of time that respondents were using their EHRs, most of these incremental differences were not statistically significant.

Some EHR vendors in some of the nutrition content areas had significantly higher or lower favorable responses compared with all other EHR vendor responses combined (Table 7). The number of respondents using many of the lower ranked and unranked vendors was too small for statistical analysis. Table 8 shows the average and range of percent favorable responses by vendor for all 5 nutrition content areas combined as well as the number of nutrition content areas that the vendor was significantly better, worse, or no different when compared with all other vendors combined. Excluding the nonranked vendors, the 2014 KLAS ranking significantly $(P<.01)$ correlated to the EHR vendors' average favorable responses (Table 8 ).

Combining the 2014 survey groups, A.S.P.E.N. members and nonmembers, $63 \%$ of respondents reported entering PN orders electronically (Table 9). Dietitians reported a significantly lower percentage of entering PN orders electronically compared with the other disciplines combined, but there were no significant differences in the reported rate by the other disciplines. There were some significant differences between disciplines in the reporting of use of various measures to limit order entry errors, as shown in Table 9. Fifty-four percent of respondents reported that their pharmacy software was different from their EHR, and again there were significant differences in these responses based on discipline. Seventy-one percent of the respondents reported their institution used an automated compounding device (ACD) for compounding PN with no difference in responses between disciplines. Two different survey questions addressed whether the respondents' EHR had a direct interface to the ACD with similar but slightly different response rates between the 2 questions ( $32 \%$ vs $28 \%$ ), but this was probably due to the fact that 600 respondents answered one of these questions and only 416 answered the other question. In the situations in which there was not a direct interface between the EHR and the ACD, the use of technicians to enter the PN orders into the ACD was relatively low compared with pharmacists.

Table 10 compares the responses to the PN survey questions from the 2014 EHR survey with those from the 2003 and 2011 PN surveys. Several of these questions were not included in the 
Table 7. Favorable Responses by Discipline, Length of Time EHR in Use, and Vendor for Each Nutrition Content Area Combining All 3 Survey Results (2012 A.S.P.E.N. Members, 2014 A.S.P.E.N. Members, and 2014 Non-A.S.P.E.N. Members). ${ }^{a}$

\begin{tabular}{|c|c|c|c|c|c|}
\hline \multirow[b]{2}{*}{ Characteristic } & \multicolumn{5}{|c|}{ No./Total No. (\%) of Favorable Responses } \\
\hline & $\begin{array}{c}\text { Nutrition } \\
\text { Documentation }\end{array}$ & $\begin{array}{l}\text { Ordering Oral } \\
\text { Diets }\end{array}$ & $\begin{array}{l}\text { Ordering Oral } \\
\text { Supplements }\end{array}$ & $\begin{array}{l}\text { Ordering Tube } \\
\text { Feedings }\end{array}$ & Ordering PN \\
\hline \multicolumn{6}{|l|}{ Discipline } \\
\hline Dietitian & $571 / 1097(52)^{\mathrm{b}}$ & $602 / 1097(55)$ & $653 / 1097(60)$ & $593 / 1097(54)$ & $576 / 1097(53)$ \\
\hline Physician & $19 / 45(42)$ & $27 / 45(60)$ & $30 / 45(67)$ & $28 / 45(62)$ & $26 / 45(58)$ \\
\hline Pharmacist & $50 / 120(42)^{\mathrm{c}}$ & $67 / 120(56)$ & $67 / 120(56)$ & $62 / 120(52)$ & $55 / 120(46)$ \\
\hline Nurse/NP & $23 / 42(55)$ & $25 / 42(60)$ & $25 / 42(60)$ & $22 / 42(52)$ & $22 / 42(52)$ \\
\hline \multicolumn{6}{|c|}{ Length of time EHR in use } \\
\hline$<1$ year & $56 / 166(34)$ & $66 / 166(40)$ & $69 / 166(42)$ & $58 / 166(35)$ & $59 / 166(36)$ \\
\hline $1-3$ years & $152 / 327(46)^{d}$ & $176 / 327(54)^{\mathrm{d}}$ & $192 / 327(59)^{\mathrm{d}}$ & $169 / 327(52)^{\mathrm{d}}$ & $164 / 327(50)^{\mathrm{d}}$ \\
\hline $3-5$ years & $164 / 302(54)$ & $162 / 302(54)$ & $187 / 302(62)$ & $168 / 302(57)$ & $154 / 302(51)$ \\
\hline $5-10$ years & $178 / 319(56)$ & $198 / 319(62)^{\mathrm{d}}$ & $202 / 319(63)$ & $207 / 319(65)^{\mathrm{d}}$ & $191 / 319(60)^{\mathrm{d}}$ \\
\hline$>10$ years & $115 / 196(59)^{\mathrm{e}}$ & $121 / 196(62)^{\mathrm{e}}$ & $127 / 196(65)^{\mathrm{e}}$ & $122 / 196(62)^{\mathrm{e}}$ & $112 / 196(57)^{\mathrm{e}}$ \\
\hline \multicolumn{6}{|c|}{ Vendor 2014 KLAS rank and identifier } \\
\hline $1-\mathrm{A}$ & $230 / 387(59)^{\mathrm{f}}$ & $242 / 387(63)^{\mathrm{f}}$ & $241 / 387(62)$ & $218 / 387(56)$ & $231 / 387(60)^{\mathrm{f}}$ \\
\hline $2-\mathrm{B}$ & $144 / 285(51)$ & $160 / 285(56)$ & $184 / 285(65)^{f}$ & $163 / 285(57)$ & $141 / 285(49)$ \\
\hline $3-\mathrm{D}$ & $50 / 92(54)$ & $48 / 92(52)$ & $47 / 92(51)$ & $50 / 92(54)$ & 49/92 (53) \\
\hline $4-\mathrm{E}$ & $85 / 206(41)^{\mathrm{g}}$ & $88 / 206(43)^{\mathrm{g}}$ & $106 / 206(51)^{\mathrm{g}}$ & $89 / 206(43)^{g}$ & $84 / 206(41)^{\mathrm{g}}$ \\
\hline $5-\mathrm{C}$ & $33 / 54(61)$ & $29 / 54(54)$ & $32 / 54(59)$ & $30 / 54(56)$ & $26 / 54(48)$ \\
\hline $6-\mathrm{L}^{\mathrm{h}}$ & $10 / 39(26)^{\mathrm{g}}$ & $17 / 39(44)$ & $21 / 39(54)$ & $18 / 39(46)$ & $12 / 39(31)^{\mathrm{g}}$ \\
\hline $\mathrm{NR}-\mathrm{F}^{\mathrm{h}}$ & $16 / 54(30)^{\mathrm{g}}$ & $23 / 54(43)$ & $26 / 54(48)$ & $21 / 54(39)^{\mathrm{g}}$ & $22 / 54(41)$ \\
\hline $\mathrm{NR}-\mathrm{G}$ & $3 / 5(60)$ & $3 / 5(60)$ & $3 / 5(60)$ & $3 / 5(60)$ & $3 / 5(60)$ \\
\hline $\mathrm{NR}-\mathrm{H}$ & $8 / 27(30)^{g}$ & $8 / 27(30)^{\mathrm{g}}$ & $10 / 27(37)^{g}$ & $9 / 27(33)^{\mathrm{g}}$ & $10 / 27(37)$ \\
\hline $\mathrm{NR}-\mathrm{I}$ & $1 / 2(50)$ & $0 / 2(0)$ & $0 / 2(0)$ & $0 / 2(0)$ & $0 / 2(0)$ \\
\hline $\mathrm{NR}-\mathrm{J}$ & $1 / 4(25)$ & $1 / 4(25)$ & $2 / 4(50)$ & $1 / 4(25)$ & $1 / 4(25)$ \\
\hline $\mathrm{NR}-\mathrm{K}$ & $4 / 7(57)$ & 4/7 (57) & 4/7 (57) & $3 / 7$ (43) & 4/7 (57) \\
\hline $\mathrm{NR}-\mathrm{M}$ & $11 / 23(48)$ & $13 / 23(57)$ & $13 / 23(57)$ & $11 / 23(48)$ & $10 / 23(43)$ \\
\hline
\end{tabular}

“2014 Best in KLAS Awards: Software and Services,” Jan 2015. (C) 2016 KLAS Enterprises, LLC. All rights reserved. www.KLASresearch.com. A.S.P.E.N., American Society for Parenteral and Enteral Nutrition; EHR, electronic health record; NP, nurse practitioner; NR, not ranked by KLAS; PN, parenteral nutrition.

a"Favorable Responses" is a combination of the "Highly" and "Moderately" responses, and "Unfavorable Responses" is a combination of "Usually,"

"Needs improvements," and "Serious concerns" responses.

${ }^{\mathrm{b}} P<.05$ - discipline's score significantly better than the other disciplines listed combined.

${ }^{\mathrm{c}} P<.05$ - discipline's score significantly worse than the other disciplines listed combined.

${ }^{\mathrm{d}} P<.05$ - group's responses significantly better than previous group.

${ }^{\mathrm{e}} P<.05-10$-year group responses significantly better than the $<1$-year group.

${ }^{\mathrm{f}} P<.05$ - vendor's responses significantly better than all other vendors combined.

${ }^{\mathrm{g}} P<.05$ - vendor's responses significantly worse than all other vendors combined.

${ }^{\text {h}}$ Same vendor but had a different EHR application in the 2012 survey (F) than in the 2014 survey (L).

2003 PN survey. There has been a significant increase in the percentage of respondents indicating that the PN orders are being entered via computerized provider order entry (CPOE) from 2003 to 2011 to $2014(29 \%$ vs $33 \%$ vs $63 \%, P<.05)$. There was also a significant increase in the responses indicating the use of checkboxes vs free text entry of the PN orders to limit order entry errors from $2011-2014$ surveys (50\% vs $60 \%$, $P<.05$ ).

Two different questions addressed the issue of whether a direct interface from the EHR to the ACD was present in the respondent's organization, with one question about the method used for entering the PN orders into the "pharmacy system" and the other about the method of entering the PN orders into the ACD. The number of respondents who answered these 2 questions was significantly different, so the percentages using a direct interface were different but similar, and in both cases, they were significantly higher in the 2014 survey compared with the 2011 survey ( $32 \%$ vs $15 \%$ and $28 \%$ vs $19 \%, P<.05$ ) (Table 10).

The reported percentage of technicians entering PN orders into the "pharmacy system" and the percentage of technicians entering the PN orders into the ACD were significantly higher in the 2011 survey compared with the 2014 survey (37/337 [11\%] vs $50 / 600[8 \%], P<.05 ; 112 / 396$ [28\%] vs $68 / 416$ 
Table 8. Comparison of Favorable Response Percentages Between EHR vendors and Relationship to 2014 KLAS Ranking Combining All 2012 and 2014 EHR Survey Results.

\begin{tabular}{|c|c|c|c|c|c|c|c|}
\hline \multirow[b]{2}{*}{2014 KLAS Rank ${ }^{c}$} & \multirow[b]{2}{*}{ EHR Vendor } & \multirow[b]{2}{*}{ No. Using ${ }^{\mathrm{d}}$} & \multicolumn{2}{|c|}{$\%$ Favorable Responses ${ }^{\mathrm{a}}$} & \multicolumn{3}{|c|}{ Comparison to Other Vendors ${ }^{b}$} \\
\hline & & & Average $^{\mathrm{e}}$ & Range & Better & No Different & Worse \\
\hline 1 & A & 387 & 60.0 & $56-63$ & 3 & 2 & 0 \\
\hline 2 & $\mathrm{~B}$ & 285 & 55.6 & $49-65$ & 1 & 4 & 0 \\
\hline 3 & $\mathrm{D}$ & 92 & 52.8 & $51-54$ & 0 & 5 & 0 \\
\hline 4 & $\mathrm{E}$ & 206 & 43.8 & $41-51$ & 0 & 0 & 5 \\
\hline 5 & $\mathrm{C}$ & 54 & 55.6 & $48-61$ & 0 & 5 & 0 \\
\hline 6 & $L^{f}$ & 39 & 40.2 & $26-54$ & 0 & 3 & 2 \\
\hline NR & $\mathrm{F}^{\mathrm{f}}$ & 54 & 40.2 & $30-48$ & 0 & 3 & 2 \\
\hline NR & $\mathrm{G}$ & 5 & 60.0 & 60 & 0 & 5 & 0 \\
\hline NR & $\mathrm{H}$ & 27 & 33.4 & $30-37$ & 0 & 1 & 4 \\
\hline NR & I & 2 & 12.5 & $0-50$ & 0 & 5 & 0 \\
\hline NR & $\mathrm{J}$ & 4 & 30.0 & $25-50$ & 0 & 5 & 0 \\
\hline NR & $\mathrm{K}$ & 7 & 54.2 & $43-57$ & 0 & 5 & 0 \\
\hline NR & M & 23 & 50.6 & $43-57$ & 0 & 5 & 0 \\
\hline
\end{tabular}

“2014 Best in KLAS Awards: Software and Services,” Jan 2015. C 2016 KLAS Enterprises, LLC. All rights reserved. www.KLASresearch.com. EHR, electronic health record; NR, not ranked.

a"Favorable Responses" is a combination of the "Highly" and "Moderately" responses, and "Unfavorable Responses" is a combination of "Usually," "Needs improvements," and "Serious concerns" responses. The average and range of the favorable responses for the 5 nutrition content areas combined are shown.

${ }^{b}$ Number of nutrition content areas that are statistically significantly better or worse or no difference compared with all other vendors combined for that nutrition content area.

${ }^{c} \mathrm{KLAS}$ is a nonprofit organization that annually publishes rankings of EHR vendors.

${ }^{\mathrm{d}}$ Number of respondents from surveys using this EHR vendor.

${ }^{\text {e}}$ Excluding the nonranked vendors, the 2014 KLAS ranking significantly $(P<.01)$ correlated to the EHR vendor's average favorable responses.

fSame vendor but had a different EHR application in the 2012 survey (F) than in the 2014 survey (L).

$[16 \%], P<.05$, respectively). There was a progressive increase in the use of a direct interface to the ACD from 2003 to 2011 to $2014(16 \%$ vs $19 \%$ vs $28 \%, P<.05)$; however, the difference between the 2003 and 2011 surveys was not significantly different (Table 10). The percentage of respondents reporting use of an ACD to compound PN was significantly higher in the 2003 survey compared with the 2011 and 2014 surveys $(88 \%$ vs $67 \%$ vs $71 \%, P<.05)$ but the percentage was not significantly different between the 2011 and 2014 surveys.

The responses regarding the effect of EHR on time required to complete their daily tasks were fairly evenly split between taking longer time, no difference, or shorter time $(30 \%, 40 \%$, and $30 \%$, respectively) (Table 11 ). The only significant difference when analyzed by discipline was that the pharmacists had a significantly lower percentage of responses indicating the EHR resulted in a shorter time to complete their daily tasks compared with all other disciplines combined (10/60 [17\%] vs $191 / 609$ [31\%], $P<.05)$. The longer the length of time the EHR was in use, there was a significant increase in the percentage of responses for shorter time and decrease in responses for longer time to complete daily tasks. There were no significant differences among vendors regarding the responses for longer time to complete daily tasks, but 2 vendors had a significantly higher percentage of shorter time responses, and 1 vendor had a significantly lower percentage of short time responses compared with all other vendors.

\section{Discussion}

The Institute of Medicine (IOM) and various governmental agencies have been recommending and encouraging healthcare organizations and physicians to convert from paper charts to EHRs since the early 1990s to improve the quality of patient care and efficiency of delivering the care. ${ }^{1}$ However, it was not until after the Health Information Technology for Economic and Clinical Health (HITECH) Act, a part of the American Recovery and Reinvestment Act (ARRA), was enacted in February $2009^{4-6}$ that a significant and sustained implementation of EHRs in hospitals and physician offices occurred. This has been mainly due to the "carrot and the stick" approach implemented by this act in which hospitals and physician offices that had or implemented an EHR between 2011 and 2015 received significant incentive payments from the government (the "carrot") while incurring significant penalties in the form of cuts in Medicare reimbursements if an EHR was not implemented by 2015 (the "stick"). The increase in implementation of EHRs was evident in a significant increase from 2012-2014 A.S.P.E.N. membership surveys in the percentages of respondents using an EHR (86\% vs $94 \%, P<.05)$ and being within the first year of EHR implementation $(11 \%$ vs $16 \%, P<.05)$.

Compared with a paper chart system, EHRs can provide more comprehensive, quicker, and easier access to information about the patient, including historical information and 
Table 9. Comparison by Discipline of Process Used to Order and Prepare PN for 2014 A.S.P.E.N. Member and Nonmember EHR Surveys Combined. ${ }^{\text {a }}$

\begin{tabular}{|c|c|c|c|c|c|c|}
\hline Characteristic & Dietitian & Physician & Pharmacist & Nurse/NP & Other & Total \\
\hline Method of ordering PN & $\mathrm{n}=592$ & $\mathrm{n}=20$ & $\mathrm{n}=60$ & $\mathrm{n}=13$ & $\mathrm{n}=4$ & $\mathrm{n}=689$ \\
\hline Handwritten & $228(39)$ & $4(20)$ & $17(28)$ & $2(15)$ & $2(50)$ & $253(37)$ \\
\hline Nonstandard & 20 & 1 & 1 & 0 & 0 & 22 \\
\hline Standard & 208 & 3 & 16 & 2 & 2 & 231 \\
\hline Electronic & $364(61)^{b}$ & $16(80)$ & $43(72)$ & $11(85)$ & $2(50)$ & $436(63)$ \\
\hline Nonstandard & 82 & 3 & 9 & 0 & 1 & 95 \\
\hline Standard & 282 & 13 & 34 & 11 & 1 & 341 \\
\hline Used to limit order entry errors $^{c}$ & $\mathrm{n}=410$ & $\mathrm{n}=17$ & $\mathrm{n}=50$ & $\mathrm{n}=11$ & $\mathrm{n}=3$ & $\mathrm{n}=491$ \\
\hline Limit space in free text fields & $135(33)^{\mathrm{b}}$ & $4(24)$ & $9(18)^{\mathrm{b}}$ & $1(9)$ & $0(0)$ & $149(30)$ \\
\hline Use checkboxes instead of free text & $251(61)$ & $11(65)$ & $29(58)$ & $4(36)$ & $1(33)$ & $296(60)$ \\
\hline Auto-populate as many fields as possible & $161(39)^{\mathrm{b}}$ & $10(58)$ & $30(60)^{b}$ & $2(18)$ & $1(33)$ & $204(42)$ \\
\hline Maintain entire order on a single screen & $168(41)$ & $6(35)$ & $25(50)$ & $5(45)$ & $1(33)$ & $205(42)$ \\
\hline $\begin{array}{l}\text { Dosing guidelines and decision support tools are built into } \\
\text { the system }\end{array}$ & $201(49)$ & $15(88)^{\mathrm{b}}$ & $24(48)$ & $5(45)$ & $1(33)$ & $246(50)$ \\
\hline $\begin{array}{l}\text { Order cannot be submitted until all required fields are } \\
\text { complete }\end{array}$ & $213(52)$ & $12(71)$ & $29(58)$ & $8(73)$ & $1(33)$ & $263(54)$ \\
\hline $\begin{array}{l}\text { Pharmacy computer software system separate from } \\
\text { organization's EHR }\end{array}$ & $\mathrm{n}=533$ & $\mathrm{n}=20$ & $\mathrm{n}=60$ & $\mathrm{n}=13$ & $\mathrm{n}=4$ & $\mathrm{n}=630$ \\
\hline Yes & $304(57)^{b}$ & $10(50)$ & $20(33)^{\mathrm{b}}$ & $3(23)^{\mathrm{b}}$ & $2(50)$ & $339(54)$ \\
\hline Method of data entry into pharmacy system & $\mathrm{n}=514$ & $\mathrm{n}=17$ & $\mathrm{n}=57$ & $\mathrm{n}=9$ & $\mathrm{n}=3$ & $\mathrm{n}=600$ \\
\hline Automatic electronic interface with EHR & $168(33)$ & $6(35)$ & $10(17)^{\mathrm{b}}$ & $3(33)$ & $1(33)$ & $188(32)$ \\
\hline Barcode entry from a printed label/requisition & $23(4)$ & $1(6)$ & $1(2)$ & $1(11)$ & $0(0)$ & $26(4)$ \\
\hline Manual entry from a printed label/requisition (technician) & $16(3)$ & $1(6)$ & $3(5)$ & $0(0)$ & $0(0)$ & $20(3)$ \\
\hline Manual entry from a printed label/requisition (pharmacist) & $61(12)^{b}$ & $1(6)$ & $19(33)^{b}$ & $3(33)$ & $0(0)$ & $84(14)$ \\
\hline Manual entry from a written order form (technician) & $27(5)$ & $1(6)$ & $2(4)$ & $0(0)$ & $0(0)$ & $30(5)$ \\
\hline Manual entry from a written order form (pharmacist) & $118(23)$ & $3(17)$ & $16(28)$ & $1(11)$ & $2(67)$ & $140(23)$ \\
\hline Other & $101(20)$ & $4(24)$ & $6(11)$ & $1(11)$ & $0(0)$ & $112(19)$ \\
\hline Do you use ACD for PN compounding? ${ }^{\mathrm{d}}$ & $\mathrm{n}=381$ & $\mathrm{n}=12$ & $\mathrm{n}=60$ & $\mathrm{n}=9$ & $\mathrm{n}=3$ & $\mathrm{n}=465$ \\
\hline Yes & $269(71)$ & $6(50)$ & $46(76)$ & $7(78)$ & $2(67)$ & $330(71)$ \\
\hline How are PN orders entered into ACD? & $\mathrm{n}=339$ & $\mathrm{n}=13$ & $\mathrm{n}=52$ & $\mathrm{n}=9$ & $\mathrm{n}=3$ & $\mathrm{n}=416$ \\
\hline Manual entry (technician) & $55(16)$ & $4(31)$ & $8(16)$ & $1(11)$ & $0(0)$ & $68(16)$ \\
\hline Manual entry (pharmacist) & $186(55)$ & $6(46)$ & $34(65)$ & $6(67)$ & $2(67)$ & $233(56)$ \\
\hline Automatic electronic interface with EHR & $99(29)$ & $3(23)$ & $10(19)$ & $2(22)$ & $1(33)$ & $115(28)$ \\
\hline
\end{tabular}

ACD, automated compounding device; A.S.P.E.N., American Society for Parenteral and Enteral Nutrition; EHR, electronic health record; NP, nurse practitioner; PN, parenteral nutrition.

${ }^{\text {a }}$ Not all respondents answered all questions, so the number of respondents (n) for reach question is displayed. Values are presented as number (\%).

${ }^{\mathrm{b}} P<.05$ comparing this discipline with all other disciplines combined.

${ }^{\mathrm{c}}$ Respondents were instructed to reply to all items that apply, so the percentages are those who replied to this question and do not add up to $100 \%$. Also, the choice of "Other" is not shown in the table.

${ }^{\mathrm{d} O n l y}$ includes yes and no responses; don’t know responses were excluded

records, improved legibility of the medical record, easier accessibility to the patient's electronic chart both within the hospital and remotely, and standardization of documentation and ordering processes. ${ }^{1}$ EHR implementation has also been shown to

1. Decrease radiology procedure completion times and laboratory result reporting times ${ }^{7}$

2. Decrease medication administration turnaround times ${ }^{7}$

3. Decrease the number of laboratory and radiology testing 8
4. Decrease length of hospital stay ${ }^{8}$

5. Improve the quality of patient care through increased adherence to guideline or protocol-based care ${ }^{8}$

6. Improve clinical monitoring based on large-scale screening and aggregation of data $^{8}$

7. Reduce medication prescribing errors (MPEs) and adverse drug events (ADEs) ${ }^{7-15}$

EHRs have significant potential advantages regarding the documentation and ordering of clinical nutrition as follows: 
Table 10. Comparison of the 2 A.S.P.E.N. PN Surveys (2003 and 2011) and the 2014 A.S.P.E.N. Member and Nonmember EHR Surveys Combined Regarding Responses to Questions on Processes Used to Order and Prepare PN. ${ }^{a}$

\begin{tabular}{|c|c|c|c|}
\hline Characteristic & 2003 PN Survey & 2011 PN Survey & 2014 EHR Survey \\
\hline Method of ordering PN & $\mathrm{n}=536$ & $\mathrm{n}=876$ & $\mathrm{n}=689$ \\
\hline Handwritten & $382(71)$ & $589(67)$ & $253(37)$ \\
\hline Nonstandard & NA & 45 & 22 \\
\hline Standard & NA & 544 & 231 \\
\hline Electronic & $154(29)^{\mathrm{b}}$ & $287(33)^{\mathrm{b}}$ & $436(63)^{\mathrm{b}}$ \\
\hline Nonstandard & NA & 121 & 95 \\
\hline Standard & NA & 166 & 341 \\
\hline Used to limit order entry errors $^{\mathrm{c}}$ & NA & $\mathrm{n}=114$ & $\mathrm{n}=491$ \\
\hline Limit space in free text fields & NA & $43(38)$ & $149(30)$ \\
\hline Use checkboxes instead of free text & NA & $57(50)^{\mathrm{d}}$ & $296(60)$ \\
\hline Auto-populate as many fields as possible & NA & $38(33)$ & $204(42)$ \\
\hline Maintain entire order on a single screen & NA & $57(50)$ & $205(42)$ \\
\hline Dosing guidelines and decision support tools are built into the system & NA & $62(54)$ & $246(50)$ \\
\hline Order cannot be submitted until all required fields are complete & NA & $60(53)$ & $263(54)$ \\
\hline Pharmacy computer software system separate from organization's EHR & NA & $\mathrm{n}=722$ & $\mathrm{n}=630$ \\
\hline Yes & NA & $353(49)$ & $339(54)$ \\
\hline Method of data entry into pharmacy system & NA & $\mathrm{n}=337$ & $\mathrm{n}=600$ \\
\hline Automatic electronic interface with EHR & NA & $51(15)^{\mathrm{d}}$ & $188(32)$ \\
\hline Barcode entry from a printed label/requisition & NA & $11(3)$ & $26(4)$ \\
\hline Manual entry from a printed label/requisition (technician) & NA & $23(7)^{d}$ & $20(3)$ \\
\hline Manual entry from a printed label/requisition (pharmacist) & NA & $55(16)$ & $84(14)$ \\
\hline Manual entry from a written order form (technician) & NA & $14(4)$ & $30(5)$ \\
\hline Manual entry from a written order form (pharmacist) & NA & $140(42)^{\mathrm{d}}$ & $140(23)$ \\
\hline Other & NA & $43(13)^{\mathrm{d}}$ & $112(19)$ \\
\hline Do you use ACD for PN compounding? ${ }^{e}$ & $\mathrm{n}=159$ & $\mathrm{n}=608$ & $\mathrm{n}=465$ \\
\hline Yes & $140\left(88^{f}\right)^{b}$ & $410(67)^{b}$ & $330(71)^{\mathrm{b}}$ \\
\hline How are $\mathrm{PN}$ orders entered into ACD? & $\mathrm{n}=123$ & $\mathrm{n}=396$ & $\mathrm{n}=416$ \\
\hline Manual entry (technician) & NA & $112(28)^{\mathrm{d}}$ & $68(16)$ \\
\hline Manual entry (pharmacist) & $103(84)$ & $211(53)$ & $233(56)$ \\
\hline Automatic electronic interface with EHR & $20(16)^{b}$ & $73(19)^{b}$ & $115(28)^{\mathrm{b}}$ \\
\hline
\end{tabular}

ACD, automated compounding device; A.S.P.E.N., American Society for Parenteral and Enteral Nutrition; EHR, electronic health record; NA, not available; PN, parenteral nutrition.

${ }^{a}$ Not all respondents answered all questions, so the number of respondents (n) for reach question is displayed. Values are presented as number (\%). ${ }^{\mathrm{b}} P<.05$ comparing the $2003 \mathrm{PN}$ survey to the $2011 \mathrm{PN}$ survey to the 2014 EHR survey in $2 \times 3 \chi^{2}$ table.

${ }^{c}$ Respondents were instructed to reply to all items that apply, so the percentages are those who replied to this question and do not add up to $100 \%$. Also, the choice of "Other" is not shown in the table.

${ }^{\mathrm{d}} P<.05$ comparing with the 2014 EHR survey.

'Only includes yes and no responses; don't know responses were excluded.

${ }^{\mathrm{f}}$ This percentage is different from that published in Table 7 of the $2011 \mathrm{PN}$ survey paper (2) because the table used the entire number of individuals surveyed (651) as the denominator and not the number of respondents who answered this question (159).

1. Easily assimilate nutrition-related documentation entered over multiple different hospital or outpatient encounters and between different healthcare systems

2. Provide valuable clinical decision support to the provider and other members of the care team at the time of nutrition order entry, especially for the more complex nutrition therapies such enteral nutrition (EN) and PN

3. Decrease risks of drug nutrient interactions

4. Decrease the risk of incompatibilities in PN formulas
5. Decrease the risk of transcription errors when transferring orders from paper or one electronic system to the nutrition services application or PN compounder

However, there are potential disadvantages to EHR systems as well. These systems are costly to purchase, implement, and maintain, requiring capital investments and significant human resources for information technology staff. ${ }^{16-18}$ Some studies have shown a decrease in various quality of care measures with implementation of an EHR. ${ }^{19-23}$ There can be an increased liability risk with EHRs, especially 
Table 11. Responses From 2014 A.S.P.E.N. Member and Nonmember Surveys Regarding the Effect of Using the EHR on Time to Complete Daily Tasks With Comparison by Discipline, Length of Time EHR Has Been in Use, and Vendor Used.

\begin{tabular}{|c|c|c|c|}
\hline Characteristic & Longer Time, No. (\%) & No Difference, No. (\%) & Shorter Time, No. $(\%)$ \\
\hline All $(n=673)$ & $201(30)$ & $271(40)$ & $201(30)$ \\
\hline \multicolumn{4}{|c|}{ Discipline $(\mathrm{n}=669)^{\mathrm{a}}$} \\
\hline Dietitian & $173(30)$ & $223(39)$ & $181(31)$ \\
\hline Physician & $6(30)$ & $9(45)$ & $5(25)$ \\
\hline Pharmacist & $20(33)$ & $30(50)$ & $10(17)^{\mathrm{b}}$ \\
\hline Nurse & $2(16)$ & $5(42)$ & $5(42)$ \\
\hline \multicolumn{4}{|c|}{ Time EHR used $(n=673)$} \\
\hline$<1$ year & $38(42)^{\mathrm{c}}$ & $32(35)$ & $21(23)^{\mathrm{d}}$ \\
\hline $1-3$ years & $65(34)$ & $83(44)$ & $41(22)$ \\
\hline $3-5$ years & $49(30)$ & $70(44)$ & $41(26)$ \\
\hline $5-10$ years & $33(23)$ & $52(35)$ & $62(42)$ \\
\hline$>10$ years & $16(19)$ & $34(40)$ & $36(42)$ \\
\hline \multicolumn{4}{|c|}{ Vendors by KLAS rank $(\mathrm{n}=675)^{\mathrm{e}}$} \\
\hline $1-\mathrm{A}$ & $66(28)$ & $88(37)$ & $85(35)^{\mathrm{f}}$ \\
\hline $2-\mathrm{B}$ & $53(33)$ & $71(44)$ & $36(23)^{\mathrm{g}}$ \\
\hline $3-\mathrm{D}$ & $15(31)$ & $11(23)^{\mathrm{h}}$ & $22(46)^{f}$ \\
\hline $4-E$ & $34(33)$ & $46(44)$ & $24(23)$ \\
\hline $5-\mathrm{C}$ & $9(28)$ & $16(50)$ & $7(22)$ \\
\hline $6-\mathrm{L}$ & $16(43)$ & $13(35)$ & $8(22)$ \\
\hline NR (all others) & $15(28)$ & $20(36)$ & $20(36)$ \\
\hline
\end{tabular}

“2014 Best in KLAS Awards: Software and Services,”Jan 2015. (c) 2016 KLAS Enterprises, LLC. All rights reserved. www.KLASresearch.com. A.S.P.E.N., American Society for Parenteral and Enteral Nutrition; EHR, electronic health record; NR, nor ranked.

a'Excluded 4 respondents who chose "Other" for discipline and no significant difference among disciplines regarding proportion that replied takes longer time or no differences.

${ }^{\mathrm{b}} P<.05$ - compared with all other disciplines, pharmacist responders had a significantly lower percentage of responses for shorter time.

${ }^{\mathrm{c}} P<.05$ - significant decrease in percent answering longer time with increasing length of time EHR used.

${ }^{\mathrm{d}} P<.05$ - significant increase in percent answering shorter time with increasing length of time EHR used.

${ }^{\mathrm{e}}$ Some respondents chose more than 1 vendor, which is why the $\mathrm{n}$ for vendors is greater than the $\mathrm{n}$ for all.

${ }^{\mathrm{f}} P<.05$ - compared with all other vendors, vendors received a significantly higher percentage of responses for shorter time.

${ }^{\mathrm{g}} P<.05$ - compared with all other vendors, vendors received significantly lower percentage of responses for shorter time.

${ }^{\mathrm{h}} P<.05$ - compared with all other vendors, vendor received significantly lower percentage of responses for no difference.

during the implementation phase until the end users get through their learning curve, any glitches in the system are resolved, and the system is optimized. ${ }^{1,24}$

Also, physicians are generally resistant to implementing EHRs due to the drastic change in how they practice and the steep learning curve when implementing an EHR. This often results in physicians spending more time to complete the same tasks as before EHR implementation, leading to significant anxiety and frustration. ${ }^{16,25}$ In 2005 , Poissant et $\mathrm{al}^{25}$ conducted a systematic review of studies analyzing the impact of EHRs on time efficiency of physicians and nurses. Time efficiency was examined for nurses in 12 studies and for physicians in 12 studies. Using a weighted average approach to combine study results, nurses spent $24.5 \%$ and $23.5 \%$ less time documenting per shift with bedside terminals and central station desktops, respectively, compared with paper charting. Using bedside or point-of-care systems, physicians' documentation time increased by $17.5 \%$. However, when physicians used central station desktops for documentation and CPOE, their work time increased by $98.1 \%-328.6 \%$ with a weighted average of $238.4 \%$ compared with paper. However, these studies did not include in their analysis the time savings that physicians gained with CPOE by not having to search for the paper chart. Also, many of these studies were performed in the 1990s and early 2000s. With advances in EHR documentation tools, these results may be very different with the currently available systems.

In our 2014 EHR survey, $40 \%$ of the respondents found that the EHR did not significantly change the amount of time required to complete their daily tasks while $30 \%$ felt that it significantly increased the time requirement and the remaining $30 \%$ stated that it shortened the time required (Table 11). The only significant differences in these responses among the different disciplines were that pharmacists had a significantly lower percent response that the EHR shortened the time required to complete their daily tasks. As one would anticipate, the longer that the respondents had used their EHR, the lower the percentage of longer time responses and the higher the percentage of shorter time responses. There were also some differences in response to this time question among vendors. The vendors with the first and third 2014 KLAS ranking had a significantly higher percentage of shorter time responses, while 
the second ranked vendor had a significantly lower percentage of this response compared with all other vendors combined. However, for all vendors, longer time to complete daily tasks was selected about $30 \%$ of the time with no significant differences among vendors, so there remains significant opportunity for improvement in efficiency for all vendors.

Many of the reported adverse consequences of EHR implementation are related to the EHR build, customization, implementation, and optimization processes; the mode and extent of end user education and training, both at the time of implementation and during ongoing optimization; and the institutional policies, procedures, and protocols governing the various different workflows within the EHR. ${ }^{1,24}$ This is why it is important that clinicians, the people actually caring for the patient, be intimately involved in all of these aspects to maximize the benefits and mitigate the potential pitfalls. This especially includes nutrition and nutrition support clinicians.

The 2012 A.S.P.E.N. membership EHR survey assessed the safety and efficacy of EHRs in 5 nutrition content areas, including (1) nutrition documentation, (2) ordering oral diets, (3) ordering ONS, (4) ordering tube feedings, and (5) ordering PN. The "favorable" responses (defined as "highly" or "moderately" safe and effective) ranged from $50 \%-62 \%$ for each of these areas, indicating a significant opportunity for improvement. ${ }^{1}$ However, the 2014 A.S.P.E.N. membership follow-up EHR survey did not show any significant improvement in any of these areas, and 2 of the areas, ordering ONS and ordering $\mathrm{PN}$, had a significant decrease in favorable responses $(62 \%$ to $54 \%$ and $55 \%$ to $44 \%$, respectively, $P<.05$ ) (Table 6 ). The favorable responses from the 2014 non-A.S.P.E.N. member EHR survey was higher for each of the 5 nutrition content areas compared with the 2014 A.S.P.E.N. member survey, but the differences were statistically significant only for ordering PN. When the responses from all 3 of these surveys were combined, the overall percentage of favorable responses for the 5 nutrition content areas ranged from $51 \%-59 \%$, with ordering ONS having significantly higher favorable responses compared with each of the other 4 areas and ordering oral diets having significantly higher favorable response compared with nutrition documentation (Table 6). The only statistically significant differences between the different disciplines was that dietitians had a higher percentage of favorable responses and pharmacists a lower percentage of favorable responses compared with all other disciplines combined regarding nutrition documentation (Table 7). So there does not appear to have been any significant improvement in the nutrition content and functionality of the commercially available EHRs from early 2012 to late 2014

Combining all 3 EHR surveys, 2012 and 2014 A.S.P.E.N. member and 2014 non-A.S.P.E.N. member surveys, the favorable response rates for all 5 nutrition content areas were significantly higher when comparing those respondents who had been using their EHR for 1-3 years or $>10$ years compared with those in their first year of use. There was a trend of incremental increases in the favorable response rates for all 5 nutrition content areas as the length of time the EHR had been in use; however, most of these incremental differences were not statistically significant (Table 7). While one may assume that the increase in favorable responses with increasing length of time of use of the EHR is due to optimization and enhancements in the configuration and build in the EHR, it is also possible that the longer the EHR had been in use, the clinicians had developed "workarounds" for the deficiencies and limitations in the system or had simply resigned themselves to the fact that the system was the best that it could be and therefore gave the EHR a higher rating. There was no way to determine from this survey which of these factors could have influenced the higher ratings for EHRs that had been in use longer. However, even in the respondents who had been using their EHR for $>10$ years, the favorable response rates for the 5 nutrition content areas ranged from $57 \%-65 \%$, which was still not very good.

The relationship between the favorable responses for each of the 5 nutrition content areas and the EHR vendor was analyzed by combining all 3 of the EHR surveys (Table 7). There was a significant correlation between the average favorable responses for all 5 nutrition content areas of the 6 ranked EHR vendors and their 2014 KLAS ranking (Table 8). The EHR ranked \#1 in the 2014 KLAS EHR ranking had the highest averaged favorable responses combining all 5 nutrition content areas and statistically significant higher favorable response rates in 3 of the 5 nutrition content areas compared with all other vendors combined (Table 8). However, this EHR vendor still had an average favorable response rate of only $60 \%$, with a range of $56 \%-63 \%$. So there is still an opportunity for improvement in the nutrition content and functionality even if using the top-rated EHR vendors.

$\mathrm{PN}$ is the most complex medication administered to patients with $>40$ individual components, including amino acids, dextrose, lipid emulsions, electrolytes, vitamins, trace elements, insulin, and other medications, as well as solubilizers and preservatives. Also, it has the potential to cause patients significant harm, especially when errors occur. ${ }^{26,27}$ In 1998, A.S.P.E.N. first published the "Safe Practices for Parenteral Nutrition Formulations" that were clinical guidelines designed to improve the safety of prescribing, formulating, and administering $\mathrm{PN}$ and to decrease the risks of death and complications that had previously been reportedly related to this therapy, and these were updated in 2004. ${ }^{28,29}$ Despite these efforts, concerns for ongoing PN-related safety issues led A.S.P.E.N. to conduct a Parenteral Nutrition Safety Summit on September 23, 2011, that was also endorsed by the Institute of Safe Medication Practices. ${ }^{30}$ Since that time, A.S.P.E.N. has published 2 additional PN safety documents as recommendations and clinical guidelines. $^{31,32}$

In 2003, A.S.P.E.N. conducted a PN survey study, and 61\% of the 651 respondents reported that PN orders needed clarification in up to $10 \%$ of the patients with the 3 most common 
reasons being illegible writing, missing essential nutrient, or incorrect or unstable macronutrient content. ${ }^{33}$ Sixty percent of the respondents reported 1-5 PN ordering errors per month, and 5\% reported over $11 \mathrm{PN}$ ordering errors per month. Patient harm from PN errors within the previous 2 years of the survey had been observed by $46 \%$ of the respondents with $35 \%$ of the adverse events requiring increased patient monitoring, $25 \%$ resulted in temporary or permanent harm, $3.3 \%$ caused a nearfatal complication, and $1.5 \%$ resulted in a death. The survey showed poor compliance with the A.S.P.E.N. PN Safe Practices. A.S.P.E.N. conducted a second PN survey study in $2011^{2}$ that had some of the same questions from the 2003 survey. The authors concluded that there was no significant improvement in the compliance with A.S.P.E.N. PN Safe Practices between the 2 studies.

Six questions from the $2011 \mathrm{PN}$ survey were included in our 2014 EHR study to analyze any improvements in the areas of EHRs and ordering and preparing PN. In the 2014 survey, there were some statistically significant differences in responses to some of these questions when one discipline of respondents was compared with all other disciplines combined (Table 9). This raises the possibility of different disciplines having a different perception of the questions or a different depth of knowledge of the PN workflow within their institution. Table 10 compares the responses to these 6 questions between the 2003 and 2011 PN surveys and the 2014 EHR survey, A.S.P.E.N. members and nonmembers combined. There has been a statistically significant increase in the use of electronic PN ordering from the 2003 to 2011 to 2014 surveys (29\% to $33 \%$ to $63 \%, P$ $<.05$ ). The only significant difference in the use of configuration or functionality to limit PN ordering errors between the 2011 and 2014 surveys was a higher percentage of using more checkboxes and less free text fields in the 2014 survey $(60 \%$ vs $50 \%, P<.05)$. The reported use of an ACD for compounding PN significantly decreased from the 2003 survey to the 2011 survey $(88 \%$ vs $67 \%, P<.05)$ and was about the same between the 2011 and 2014 surveys ( $67 \%$ vs $71 \%$ ). The reason for this difference is unclear. A positive change was a progressive and statistically significant increase in the use of a direct electronic interface between the EHR and the ACD from 2003 to 2011 to $2014(16 \%$ vs $19 \%$ vs $28 \%, P<.05)$.

Nutrition clinicians need to pursue opportunities to learn more about clinical informatics and actively pursue participation in informatics committees within their healthcare organizations to enhance the nutrition content within their EHR by being involved in vendor selection, initial build, implementation, and optimization. Also, nutrition-related societies and organizations need to form clinical informatics committees that can help educate their members and can work with EHR vendors to expand and optimize the nutrition content of their EHR systems.

Many of the weaknesses of this study are similar to other studies using survey methodology. Average response rates to surveys vary widely and depend on how the survey is conducted and who is being surveyed. Typical ranges of response rates that have been reported are $60 \%-90 \%$ for employees, $5 \%-40 \%$ for customers or members of an organization, and $1 \%-20 \%$ for the general public. ${ }^{34} \mathrm{~A}$ review of response rates on online surveys revealed response rates ranging from $23 \%-47 \% .{ }^{35}$ A 2009 meta-analysis ${ }^{36}$ compared the response rates for email vs paper surveys from 35 published studies. The surveys were on a variety of different topics, and the respondents varied between college students and faculty, professionals (including doctors, directors, and managers), employees, and general population. The study found that email surveys had a lower response rate than paper surveys $(33 \%$ [range, $5 \%-85 \%$ ] vs $53 \%$ [range, $11 \%-85 \%$ ]). The only 2 factors that had a significant effect on the differences in response rates was the population surveyed (college students and faculty had similar response rates to email and paper surveys) and follow-up reminders. However, the author felt the correlation with follow-up reminders was biased by one large study so did not feel that follow-up reminders significantly improved response rates.

The response rate of $14.9 \%$ in our 2012 EHR survey was relatively low but is within the above-reported ranges for members of an organization. The response rates to the 2014 A.S.P.E.N. member and nonmember surveys were even lower. This may be because the 2012 survey was open for 3 weeks with a reminder email in the middle of this period, while the 2014 surveys were open for about 2 weeks with no email reminder. In the 2012 survey, 619 (72\%) responses were received in the first 2 weeks, which is still a higher response rate than the 2014 A.S.P.E.N. member survey $(10.7 \%$ vs $6.4 \%$, $P<.05)$, with the remainder being submitted after the email reminder. Other possible reasons for the low response rate with the 2014 A.S.P.E.N. membership survey are that it was conducted at a different time of the year and it was a repeat survey, so individuals who responded in the 2012 survey may have been "burnt out" on surveys and did not want to take the time to participate in the follow-up survey. Another possible reason for the low response rates to the 2014 non-A.S.P.E.N. member surveys was that many of these individuals may not have been involved in direct patient care, so a survey on EHR systems was not applicable to them. Some of the members of A.S.P.E.N. are also members of the ASN and/or the Academy and were instructed in the survey communication not to complete the survey multiple times. This reception of the survey from different organizational lists may have falsely lowered the response rate as the denominator for the response rate was the full membership list. Also, individuals may have been receiving multiple other types of email surveys during the same time period and may have been "burnt out" on completing email surveys.

Because of the low response rates, the findings of our EHR surveys may not be representative of all A.S.P.E.N. or other society members. Most respondents were members of A.S.P.E.N., ASN, or the Academy and have additional education, training, experience, and/or interest in clinical nutrition and nutrition 
support, so their responses may or may not be reflective of how physicians, dietitians, pharmacists, and nurses in general would have responded to these questions. On the other hand, who is better equipped to assess the nutrition content of an EHR than clinicians who have this additional expertise?

While $86 \%$ of the respondents in the 2012 survey and $92 \%$ in the 2014 survey (combining A.S.P.E.N. members and nonmembers) indicated that they were using an EHR currently, this figure may not be representative of the percentage of A.S.P.E.N. members or of hospitals in the United States that are currently using an EHR since individuals who are using an EHR may have been more likely to respond to the survey than those who are not. Also, $84 \%(1097 / 1304)$ of the respondents to the safety and efficacy questions were dietitians, so the responses may not be representative of the other disciplines involved in the survey. However, there were few differences in responses between the disciplines, and these differences were called out when found. The safety and effectiveness data presented are based on subjective responses to these questions rather than more objective data such as mortality, morbidity, time studies, and rates of ADE or MPE. Also, 20\% of the respondents (18\% 2012 survey, 16\% 2014 A.S.P.E.N. members, and $29 \%$ of 2014 non-A.S.P.E.N. members) who indicated using an EHR did not respond to the safety and efficacy questions. The reason for this is unknown, but it is possible that this could have affected the survey results. There was some uncertainty in identifying the correct EHR vendor being used that could have affected the vendor safety and efficacy analysis. In the 2012 survey, 25\% (41/163) of respondents chose "Other" for their EHR vendor, but in the comments field, they specified one of the named vendors. The list of named vendors to choose from was increased in the 2014 survey, but still 12\% (20/162), including A.S.P.E.N. members and nonmembers, of the respondents who chose "Other" for their EHR vendor entered a vendor in the comments field that was one of the named vendors. However, the above respondents only account for $4 \%(61 / 1633)$ of the overall respondents who indicated they were using an EHR, so it is unlikely that this significantly affected the analysis comparing vendors.

Last, our categorization of "favorable" responses ("highly" and "moderately" "safe and effective") and "unfavorable" responses, including all other responses (see Table 1), to the safety and efficacy questions regarding the 5 nutrition content areas was reasonable and rational; however, this was somewhat arbitrary. Some may argue that only the "highly safe and effective" responses should have been considered "favorable" responses, while others may argue that "highly," "moderately," and "usually" safe and effective should have been considered "favorable" responses.

\section{Call to Action}

With the penalty phase of the HITECH Act now in effect, nearly all hospitals have or soon will have an EHR. While there are many advantages of EHRs, there are also significant disadvantages and limitations. Based on our survey results, there has been little or no significant improvement between early 2012 and late 2014 with regard to the safety and efficacy of nutrition documentation, ordering oral diets, ordering ONS, ordering tube feedings, and ordering PN in the commercially available EHRs.

Nutrition clinicians need to aggressively pursue involvement within their facilities regarding the selection, implementation, and optimization of their EHR. The goal should be to incorporate elements of the nutrition care process into the EHR with clinical decision making to improve patient nutrition care, improve efficiency, and minimize adverse outcomes. Examples include but are not limited to validated nutrition screening tools, A.S.P.E.N./Academy malnutrition criteria, guidelines for $\mathrm{EN}$ and PN safe practice, and nutrition diagnosis terminology with links to coding, standards of practice, and decision support for nutrition therapy.

Nutrition-related societies and organizations need to provide education on clinical informatics to their members. To facilitate this process, A.S.P.E.N., the Academy, and ASN should provide EHR vendors with templates for standard nutrition care processes and checklists of what nutrition models and reports are needed. Efforts to standardize these processes among institutions are necessary to optimize clinical practice and promote a system to capture outcomes of nutrition care.

\section{References}

1. Vanek VW. Providing nutrition support in the electronic health record era: the good, the bad, and the ugly. Nutr Clin Pract. 2012;27(6):718-737.

2. Boullata JI, Guenter P, Mirtallo JM. A parenteral nutrition use survey with gap analysis. JPEN J Parenter Enteral Nutr. 2013;37:212-222.

3. KLAS. KLAS Research Web site. http://www.klasresearch.com/. Accessed September 17, 2015.

4. Thomson B. Carrots and sticks: electronic health records, meaningful use, and your practice. eQuoteMD Web site. http://www.equotemd.com/ blog/carrots-and-sticks-electronic-healthrecords-meaningful-use-and-yourpractice/. Published April 2, 2015. Accessed September 21, 2015.

5. Kasa Practice Solutions. What is the HITECH Act and how does it impact my practice? Kasa Practice Solutions Web site. http://www.kasa-solutions. com/blog/hitech-act-impact-practice/. Published January 5, 2014. Accessed September 21, 2015.

6. Carroll J. Meaningful use: tasty carrot or big, brutal stick? Manag Care. 2010;19:12-16, 23.

7. Mekhjian HS, Kumar RR, Kuehn L, et al. Immediate benefits realized following implementation of physician order entry at an academic medical center. J Am Med Inform Assoc. 2002;9:529-539.

8. Chaudhry B, Wang J, Wu S, et al. Systematic review: impact of health information technology on quality, efficiency, and costs of medical care. Ann Intern Med. 2006;144:742-752.

9. Hill PM, Mareiniss D, Murphy P, et al. Significant reduction of laboratory specimen labeling errors by implementation of an electronic ordering system paired with a bar-code specimen labeling process. Ann Emerg Med. 2010;56:630-636.

10. Bates DW, Leape LL, Cullen DJ, et al. Effect of computerized physician order entry and a team intervention on prevention of serious medication errors. JAMA. 1998;280:1311-1316.

11. Upperman JS, Staley P, Friend K, et al. The impact of hospital wide computerized physician order entry on medical errors in a pediatric hospital. J Pediatr Surg. 2005;40:57-59.

12. van Rosse F, Maat B, Rademaker CM, van Vught AJ, Egberts AC, Bollen $\mathrm{CW}$. The effect of computerized physician order entry on medication pre- 
scription errors and clinical outcome in pediatric and intensive care: a systematic review. Pediatrics. 2009;123:1184-1190.

13. Bates DW, Teich JM, Lee J, et al. The impact of computerized physician order entry on medication error prevention. J Am Med Inform Assoc. 1999;6:313-321.

14. Kaushal R, Shojania KG, Bates DW. Effects of computerized physician order entry and clinical decision support systems on medication safety: a systematic review. Arch Intern Med. 2003;163:1409-1416.

15. Ammenwerth E, Schnell-Inderst P, Machan C, Siebert U. The effect of electronic prescribing on medication errors and adverse drug events: a systematic review. J Am Med Inform Assoc. 2008;15:585-600.

16. Jha AK, DesRoches CM, Campbell EG, et al. Use of electronic health records in U.S. hospitals. N Engl J Med. 2009;360:1628-1638.

17. Hillestad R, Bigelow J, Bower A, et al. Can electronic medical record systems transform health care? Potential health benefits, savings, and costs. Health Aff (Millwood). 2005;24:1103-1117.

18. Himmelstein DU, Wright A, Woolhandler S. Hospital computing and the costs and quality of care: a national study. Am J Med. 2010;123: 40-46.

19. Han YY, Carcillo JA, Venkataraman ST, et al. Unexpected increased mortality after implementation of a commercially sold computerized physician order entry system. Pediatrics. 2005;116:1506-1512.

20. King WJ, Paice N, Rangrej J, Forestell GJ, Swartz R. The effect of computerized physician order entry on medication errors and adverse drug events in pediatric inpatients. Pediatrics. 2003;112(3, pt 1):506-509.

21. Walsh KE, Adams WG, Bauchner $\mathrm{H}$, et al. Medication errors related to computerized order entry for children. Pediatrics. 2006;118:1872-1879.

22. Koppel R, Metlay JP, Cohen A, et al. Role of computerized physician order entry systems in facilitating medication errors. JAMA. 2005;293:1197-1203.

23. Harrington L, Kennerly D, Johnson C. Safety issues related to the electronic medical record (EMR): synthesis of the literature from the last decade, 2000-2009. J Healthc Manag. 2011;56:31-44.
24. Mangalmurti SS, Murtagh L, Mello MM. Medical malpractice liability in the age of electronic health records. $N$ Engl J Med. 2010;363:2060-2067.

25. Poissant L, Pereira J, Tamblyn R, Kawasumi Y. The impact of electronic health records on time efficiency of physicians and nurses: a systematic review. J Am Med Inform Assoc. 2005;12:505-516.

26. Sacks GS. Safety surrounding parenteral nutrition systems. JPEN $J$ Parenter Enteral Nutr. 2012;36(2)(suppl):20S-22S.

27. Boullata JI. Overview of the parenteral nutrition use process. JPEN $J$ Parenter Enteral Nutr. 2012;36(2)(suppl):10S-13S.

28. National Advisory Group on Standards and Practice Guidelines for Parenteral Nutrition. Safe practices for parenteral nutrition formulations. JPEN J Parenter Enteral Nutr. 1998;22:49-66.

29. Mirtallo J, Canada T, Johnson D, et al. Safe practices for parenteral nutrition. JPEN J Parenter Enteral Nutr. 2004;28:S39-S70.

30. Mirtallo JM, Guenter P. Introduction and goals of the A.S.P.E.N. parenteral nutrition safety summit. JPEN J Parenter Enteral Nutr. 2012;36(2) (suppl):7S-9S.

31. Boullata JI, Gilbert K, Sacks G, et al. A.S.P.E.N. clinical guidelines: parenteral nutrition ordering, order review, compounding, labeling, and dispensing. JPEN J Parenter Enteral Nutr. 2014;38(3):334-377.

32. Ayers P, Adams S, Boullata J, et al. A.S.P.E.N. parenteral nutrition safety consensus recommendations. JPEN J Parenter Enteral Nutr. 2014;38(3):296-333.

33. Seres D, Sacks GS, Pedersen CA, et al. Parenteral nutrition safe practices: results of the 2003 American Society for Parenteral and Enteral Nutrition survey. JPEN J Parenter Enteral Nutr. 2006;30:259-265.

34. Ray A. Typical response rates. Practical Surveys Web site. http:// practicalsurveys.com/respondents/typicalresponserates.php. Published March 20, 2006. Updated March 12, 2015.Accessed September 22, 2015.

35. Nulty DD. The adequacy of response rates to online and paper surveys: what can be done? Assess Eval High Educ. 2008; 33(3):301-314.

36. Shih TH, Fan X. Comparing response rates in e-mail and paper surveys: a meta-analysis. Educ Res Rev. 2009;4:26-40. 